\title{
Magnetic Resonance Guided Focused Ultrasound* for Fibroid Treatment - Results of the Second Radiological Gynecological Expert Meeting
}

\section{Magnetresonanzgeführter fokussierter Ultraschall zur Myombehandlung - Ergebnisse des 2. radiologisch-gynäkologischen Expertentreffens}

Authors

Affiliations
T. Kröncke ${ }^{1}$, M. David ${ }^{2}$, on behalf of the participants of the Consensus Meeting

${ }^{1}$ Department of Diagnostic and Interventional Radiology and Neuroradiology, Klinikum Augsburg

${ }^{2}$ Department of Gynecology, Charité Universitätsmedizin Berlin
Deutschsprachige Zusatzinformationen online abrufbar unter: www.thieme-connect.de/ ejournals/toc/gebfra

First publication DOI http://dx.doi.org/ 10.1055/s-0034-1399342 Fortschr Röntgenstr 2015; 187 : 480-482 (c) Georg Thieme Verlag KG Stuttgart . New York . ISSN 1438-9029

Bibliography

DOI http://dx.doi.org/

10.1055/s-0035-1546000

Geburtsh Frauenheilk 2015; 75 :

436-438 @ Georg Thieme

Verlag KG Stuttgart . New York . ISSN 0016-5751

\section{Correspondence}

PD Dr. med. Thomas Kröncke, $M B A$

Department of Diagnostic and Interventional Radiology and Neuroradiology Klinikum Augsburg Stenglinstraße 2 86156 Augsburg thomas.kroencke@ klinikum-augsburg.de

Prof. Dr. med. Matthias David Department of Gynecology Charité Universitätsmedizin Berlin

Campus Virchow-Klinikum Augustenburger Platz 1 13353 Berlin

\section{Preamble}

$\nabla$

Treating myoma using MR-guided focused ultrasound surgery (MRgFUS; synonym: MR HIFU = high-intensity focused ultrasound) is a thermoablative procedure in which focused ultrasound, under constant MR tomographic monitoring, heats the treated tissue in individual small volume increments (sonications) until the planned fibroid volume has been completely denatured. Upon completion of thermoablation, the control (contrast-enhanced MRI) indicates an absence of contrast enhancement in the treated tissue (i.e. $\mathrm{NPV}=$ non-perfused volume).

The MRgFUS procedure is organ-preserving, noninvasive and can be performed on an outpatient basis.

This treatment method is provided by only a few specialized facilities.

The aim of MRgFUS therapy is the reduction or elimination of myoma-based symptoms among affected women. Ultrasonic treatment can achieve shrinking of a fibroid. Complete remission of the fibroid should not be expected and is not the goal of treatment.

There is a consensus between the disciplines of gynecology and radiology that determination of required treatment of uterine fibroids should be based on an examination and advice by a gynecologist. Comprehensive advice regarding treatment options for symptomatic uterine fibroids encompasses not only medication-based and surgical options, but also non-surgical therapy options including uterine artery embolization (UAE) and MRgFUS. The decision for or against an alternative therapy should be made taking into account the patient's desire for, and knowledge of, therapeutic alternatives, their chances of success and limita- tions, as well as typical side effects and possible complications (informed decision).

In Germany, Austria and Switzerland, the option of MRgFUS treatment offers the possibility of a therapeutic procedure for patients with myomarelated symptoms which provides further individualization of therapy in cases of uterine fibroids.

\section{Aim of the Consensus Meeting}

$\nabla$

The intention of this second consensus meeting was the evaluation and integration of the MRgFUS procedure into the therapeutic spectrum of myoma treatment. The 14 participants in the meeting of radiological-gynecological experts, after taking into account current literature and their own experience, and after extensive discussion, came to a consensus between the two disciplines.

The panel of experts was aware that this was an assessment of the possibilities and limits of a radiological therapy held in conjunction with specialists in gynecology who do not perform the procedure themselves, but who possess expertise and experience in the diagnosis as well as medication-based and surgical treatment of disorders of female reproductive organs.

The group of experts composed of 6 radiologists and 8 gynecologists met on January 17, 2015 in Berlin for the second radiological-gynecological consensus meeting regarding MRgFUS therapy included gynecologists from Switzerland and Austria.

After extensive - and somewhat controversial discussion, the group came to a consensus regarding the following recommendations. The consensus statement is supported by the gynecologists 
and radiologists listed at the end of this work. It reflects the current state of knowledge.

\section{Structural Prerequisites for the Performance of MRgFUS Therapy}

MRgFUS should be performed only at clinics possessing the requisite expertise and experience with MRgFUS therapy. This also includes non-surgical and surgical management of side effects and complications. In addition, there should be options to initiate post-interventional pain management.

\section{Examinations Required Prior to MRgFUS Therapy \\ $\nabla$}

The choice of therapy should be based on an examination performed by a gynecologist including vaginal and/or abdominal ultrasound (as a function of the size of the uterine fibroid). A necessary prerequisite is the performance of a planning MRI using contrast medium (CM), in prone position if possible. The contrastenhanced image is also used to assess whether, and to what degree, the fibroid is perfused.

Prior to each MRgFUS the indications for hysteroscopy and fractionated curettage must be critically reviewed with respect to bleeding pattern, endometrium thickness and structure. Unremarkable cytological smear findings of the uterine cervix must have been obtained within the previous 12 months.

Likewise, prior to MRgFUS, within the context of the informed consent discussion, the patient should be informed regarding the absence of a pre-interventional histological confirmation of the presumed uterine fibroids, as is the case with all other organ-conserving myoma therapies (see also the statement of the DGGG [German Society of Gynecology and Obstetrics] "Implementation of the Medical Devices Act - Gynecological Morcellators" dated 08/29/2014).

\section{Indications for MRgFUS Therapy \\ $\nabla$}

A symptomatic uterine fibroid is an indication for MRgFUS treatment.

The uterine fibroid must be in a position location that allows safe access to the myoma for the MRgFUS. The presence of more than five myomas hinders the treatment. In cases of myomas with a diameter greater than $10 \mathrm{~cm}$, MRgFUS therapy should be critically reviewed due to the large volume of the myoma and resulting extended treatment time.

MRgFUS represents an alternative to surgical and medicationbased procedures as well as UAE. The basis for the choice of therapy should be the aim of the treatment as well as the patient's desire. Given technical feasibility, MRgFUS represents a good option for patients desiring a minimally-invasive procedure.

\section{Success Criteria for MRgFUS Therapy \\ $\nabla$}

The goal of therapy using focused ultrasound should be the largest possible non-perfused volume (NPV).

The improvement or disappearance of myoma-related symptoms should be the result of successful MRgFUS treatment. Although a reduction in volume is desired, it is considered a secondary therapeutic goal.

\section{Contraindications for MRgFUS Therapy \\ $\nabla$ \\ - Suspicion of malignancy (absolute) \\ - Pregnancy (absolute) \\ - Acute inflammatory process (absolute) \\ - Pedunculated subserosal fibroids (absolute)}

- No sufficiently accessible acoustic window for treatment (e.g. intestine in the planned path of the ultrasound beam) (absolute)

- Uterine fibroids with more than 5 myomas (relative, case-bycase decision)

- Uterine myomas with diameter greater than $10 \mathrm{~cm}$ (relative, case-by-case decision)

- Large scars in acoustic window (relative)

- Myoma in posterior wall or near os sacrum (relative)

- General contraindications with respect to MR contrast media (relative)

- Relative and absolute MRI contraindications

Data regarding interactions between MRgFUS and ulipristal acetate is insufficient and requires additional studies.

\section{MRgFUS Therapy for Patients Wishing to Become Pregnant \\ $\nabla$}

Previous case reports indicate that pregnancy is possible after MRgFUS and can be successfully accomplished, but there are still insufficient data for a recommendation.

\section{Side Effects/Complications of MRgFUS Therapy} $\nabla$

Related side effects and complications during and after MRgFUS treatment are rare:

> Pain

- Skin burns

- Inflammation of subcutaneous adipose tissue and musculature of the abdominal wall

- Paresthesia of the leg due to nerve irritation or damage

- Deep leg vein thrombosis (very rare)

- Bowel perforation (extremely rare).

After therapy, tissue components may be discharged vaginally. Increased and/or irregular bleeding may occur up to approx. three months after treatment.

\section{Post-treatment Examination after MRgFUS Therapy $\nabla$}

Post-treatment examination by a specialist is recommended approx. 6 months after MRgFUS. Imaging procedures are useful (i.e. sonography in conjunction with Doppler sonography, MRI). Further clarification is required if the therapy is unsuccessful (no improvement of symptoms and/or size progression of the myoma), or there are abnormalities in the imaging (increase in size of myoma(s) or uterus). 


\section{Outlook}

Based upon available data and experience, a revision of recommendations for MRgFUS therapy of myomas is planned in about two years.

\section{Meeting Participants}

$\nabla$

Dr. med. Alexander Beck/Berlin

Prof. Dr. med. Gerlinde Debus/Dachau

Prof. Dr. med. Markus Düx/Frankfurt a.M.

Prof. Dr. med. Dr. phil. Andreas Ebert/Berlin

Prof. Dr. med. Peyman Hadji/Frankfurt a. M.

Dr. med. Thomas Hess/Winterthur (Switzerland)

Dr. med. Friederike Hoellen/Lübeck

PD Dr. med. Peter Hunold/Lübeck

Dr. med. Hans-Christian Kolberg/Bottrop

Dr. med. Matthias Matzko/Dachau

PD Dr. med. Stefan Rimbach/Feldkirch (Austria)

PD Dr. med. Christoph Trumm/Munich

\section{Participating Professional Associations and Working Groups}

$\nabla$

AGE, Arbeitsgemeinschaft Gynäkologische Endoskopie der DGGG (Gynecological Endoscopy Working Group of the German Society of Gynecology and Obstetrics)

AGO, Arbeitsgemeinschaft Gynäkologische Onkologie der DGGG (Gynecological Oncology Working Group of the German Society of Gynecology and Obstetrics)

Berufsverband der Frauenärzte e.V. (Professional Association of Gynecologists)

DeGIR, Deutsche Gesellschaft für Interventionelle Radiologie und minimal-invasive Therapie (German Society for Interventional Radiology and Microinvasive Therapy)

DGGEF, Arbeitsgemeinschaft Gynäkologische Endokrinologie und Fortpflanzungsmedizin e.V. (Working Group for Gynecological Endocrinology and Reproductive Medicine)

DGGG, Deutsche Gesellschaft für Gynäkologie und Geburtshilfe (German Society of Gynecology and Obstetrics)

DRG, Deutsche Röntgengesellschaft (German X-ray Society) SSVIR, Swiss Society of Vascular and Interventional Radiology 